Int. J. Dev. Biol. 58: 117-126 (2014)

doi: $10.1387 / \mathrm{ijdb} .130335 \mathrm{gw}$

\title{
Evolution of mammalian pregnancy and the origin of the decidual stromal cell
}

\author{
GÜNTER P. WAGNER ${ }^{1,2}$, KORYU KIN ${ }^{1}$, LOUIS MUGLIA ${ }^{3}$ and MIHAELA PAVLIČEV ${ }^{3}$ \\ ${ }^{1}$ Department of Ecology and Evolutionary Biology and Systems Biology Institute, Yale University, New Haven, CT, \\ USA, '2Department of Obstetrics and Gynecology, Wayne State University, Detroit, MI, USA and \\ ${ }^{3}$ Cincinnati Children's Hospital, University of Cincinnati, $\mathrm{OH}, \mathrm{USA}$
}

\begin{abstract}
Reproduction in eutherian mammals is characterized by extended intrauterine retention of the fetus after implantation. We summarize evolutionary innovations that enable this form of vivipary, including early maternal recognition of pregnancy, invasive placentation, and emergence of the decidual cell type. We first review the structure of the marsupial endometrium and its relationship to that of eutherian mammals. While the tissue components of endometrium are the same in marsupials and eutherians, an important difference is the amount of stromal cells, which are much more abundant in eutherians. Moreover, the nature of the invasive placentation differs in marsupials and eutherians. In the opossum, it consists of cytoplasmatic extensions of trophoblast cells that penetrate between the luminal epithelial cells to contact maternal capillaries. In bandicoots, the trophoblast and luminal epithelial cells fuse, and the maternal epithelium is replaced by a layer of multinucleated cells. In no case has there been evidence of a direct interaction between trophoblast and stromal cells. The direct interface between the trophoblast and maternal stroma is a derived feature of eutherian mammals, coincidental with the origin of decidual cells. Gene expression studies are suggestive of "categorical reprograming" of endometrial fibroblasts during decidualization. This reprogramming suggests that the decidual cell is a distinct cell type rather than a modulation of endometrial fibroblasts. Further support for this hypothesis is the origin of derived transcription factor interactions that are necessary for the regulation of decidual gene expression, in particular the interactions between HOXA11 and CEBPB with F0X01A.
\end{abstract}

KEY WORDS: evolution of pregnancy, decidual cell, cell type evolution, viviparity, marsupial pregnancy

\section{Introduction}

Vivipary is a reproductive feature that has evolved multiple times in vertebrate history and can be found in most major clades of the vertebrate tree: sharks as representatives of cartilaginous fishes, in ray finned fishes, amphibians, lizards and of course in mammals (Blackburn, 1992, Van Dyke et al., 2014, Wourms, 1977, Wourms, 1981). Notable exceptions are birds, other archosaurs (crocodylians) and turtles, all of which coincidentally form a single reptilian clade according to recent phylogenomic research (Crawford et al., 2012, Wang et al., 2013). Vivipary is also absent form extant jawless vertebrates, which is a very small group. Nevertheless, mammalian pregnancy, in particular that of eutherian mammals, stands out in terms of its sophistication and the degree of fetalmaternal integration.

The evolution of vivipary and implantation is often discussed with a focus on the placental/fetal structures (Blackburn and Flem- ming, 2009, Mess and Carter, 2006, Mossman, 1987, Wildman et al., 2006). The placenta originates as a modification of fetal membranes, the chorion, the yolk sac and the allantois. Maternal innovations, however, are arguably as important as the innovations on the side of the fetus. In this review we synthesize what is known about the variation of endometrial structure and function and offer a model to identify the key innovations involved, on the maternal side, in the evolution of eutherian and ultimately human pregnancy.

\section{Phylogenetic relationships and comparisons}

Mammals are one of the two major clades of amniotes, the land vertebrates. These two clades are the mammals and reptiles, the

Abbreviations used in this paper: GE, glandular epithelium; LE, luminal epithelium; ES, endometrial stroma; PH\&P, precocious hatching and parturition; dPRL, decidual prolactin.

\footnotetext{
*Address correspondence to: Günter P. Wagner. Department of Ecology and Evolutionary Biology, Yale University, 165 Prospect Street, New Haven, CT-06520 USA. Tel: 203-737-3091. Fax: 203-737-3901. E-mail: gunter.wagner@yale.edu
} 
latter includes squamates (lizards and snakes), turtles and archosaurs (crocodylians and birds) (Fig. 1). The most recent common ancestor of mammals and birds thus is also the most recent common ancestor of all amniotes. The mammals have three major clades, monotremes (Echidnaand Platypus), marsupials (kangaroos, opossums and others), and the eutherians (all animals derived from the common ancestor of humans and elephants). Among these, marsupials are the most closely related to eutherian mammals, and together they form a clade called Theria (Fig. 1).

The gross morphology of the female reproductive tract is relatively conserved among amniotes (Lombardi, 1998, Schatten and Constantienscu, 2007). In egg laying reptiles, including birds, the ovary is followed by the infundibulum, then a variously structured oviduct, and finally a shell gland. The connection of the female reproductive tract to the body surface is achieved through the cloaca. The various vestments of the egg cell are produced in these three segments: yolk and the zona pellucida in the ovary, albumen in the oviduct, and the shell coat in the shell gland. The uterus of the mammalian female reproductive tract is likely homologous to the shell gland of oviparous reptiles (Lombardi, 1998). Shell gland and uterus occupy the same relative positions along the ovarian-cloacal axis, are both primarily secretory organs with similar multicellular glands and, in marsupials, the shell coat is produced in the proximal section of the uterus (Zeller and Freyer, 2001). Eutherians no longer produce a shell coat.

The variation of female reproductive biology among the three major mammalian groups, monotremes, marsupials and eutherians, can be seen as a gradient of increasing integration between fetal development and maternal physiology as well as a gradient in terms of increasing matrotrophy. In monotremes, known as the egg-laying mammals, the egg receives substantial uterine provisioning even while the fetus remains enclosed in the eggshell. In monotremes the amount of yolk invested in the ovum is already

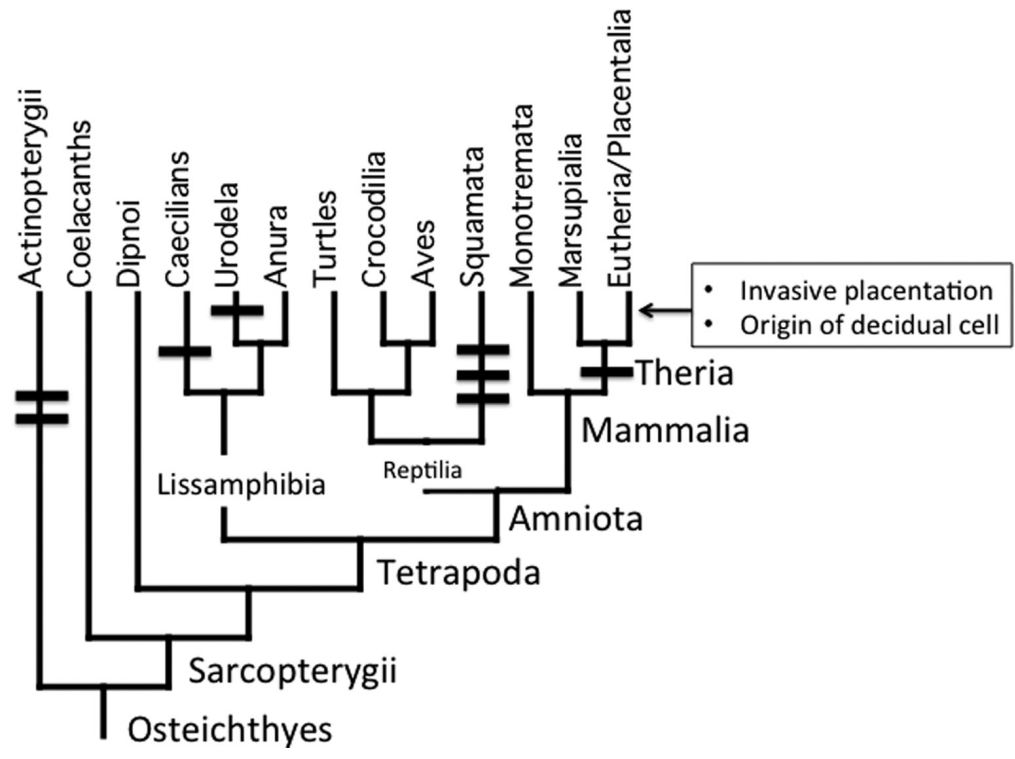

Fig. 1. Phylogenetic relationships among bony fish (technically all groups represented here belong to the clade Osteichthyes, bony fish, including mammals and humans). Hatch marks represent the origin of vivipary. Multiple hatch marks indicate clades that have evolved vivipary multiple times, in the case of squamate reptiles the number is about or more than 100. insufficient to support fetal development till hatching (Griffiths, 1978). Uterine secretions thus play a major role in support of fetal development long before placentation arose in the mammalian lineage. In Echidna, the egg is stored in a posterior facing pouch until hatching (Griffiths, 1978), foreshadowing the marsupial condition where very immature neonates are often kept in a pouch for extended periods of time (Tyndale-Biscoe and Renfree, 1987).

The marsupials are a considerably larger and more diverse group than the monotremes and consequently also have a greater variety of reproductive features (Freyer et al., 2003, Renfree, 2010, Tyndale-Biscoe and Renfree, 1987). Nevertheless, there are some shared features that suggest an intermediate stage in the evolutionary transition from egg laying to eutherian pregnancy, even though marsupials have acquired a large number of shared derived features in female reproductive biology (e.g. a three part vagina and extensive period of lactation). The features that are intermediate between monotremes and eutherians are: retention of a shell coat, early hatching from the shell coat and superficial placentation.

A distinguishing feature of marsupial gestation is its relationship to the sexual cycle. In marsupials intrauterine development is short, often shorter than the sterile sexual cycle with limited change in the maternal physiology. For instance in the gray short-tailed opossum, Monodelphis domestica, pregnancy lasts about 14 days and of those the conceptus remains in the shell coat for 10 to 12 days (Zeller and Freyer, 2001) but the sterile sexual cycle is 26 days (Fadem and Rayve, 1985). Placental attachment is limited to the last two to four days of gestation. In contrast, gestation of squamate reptiles tends to be longer than the ovarian cycle, for instance the ovarian cycle of the Anolis is about 28 days, but gestation is about 30 days (Jones et al., 1983). Gestational lengths overlap greatly between oviparous and viviparous species (Tinkle and Gibbons, 1977), suggesting that some degree of egg retention is already present in oviparous lizards. In more derived marsupials like the macropodids, pregnancy has been extended compared to the short gestation seen in Monodelphis. For instance in the tammar wallaby, Macropus eugenii, pregnancy lasts for 26 days after resumption of development (blastocysts remain dormant until the previous offspring generation has left the pouch) (Freyer et al., 2002).

Maternal recognition of pregnancy is essential for the commencement of pregnancy in eutherian mammals, and also exists in derived marsupial clades such as the wallabies and is likely derived within the marsupials (Tyndale-Biscoe and Renfree, 1987). In contrast, opossums, dasyurids and phalangerids do not have early recognition of pregnancy. This situation is likely an ancestral character for marsupials (Freyer et al., 2003).

There have been reports of invasive placentation in various marsupial species, which will be discussed below. Here, it may be mentioned that there are important differences between marsupial and eutherian invasive placentation that make comparisons less fruitful than the use of the term "invasive" for both situations suggests.

In contrast to marsupials, the gestational period of eutherians is much longer than the sterile sexual cycle, has early recognition of pregnancy and an ancestrally invasive placentation. The latter conclusion is based on ancestral state reconstructions utilizing the molecular phylogenetic 
hypotheses of the relationships among the major eutherian groups (Elliot and Crespi, 2009, Mess and Carter, 2006, Wildman et al., 2006) (Fig. 2). These investigations agree that invasive placentation arose in the stem lineage of eutherian mammals. Disagreements only exist as to the degree of invasiveness. Wildman and colleagues as well as Elliot and Crespi suggest that the ancestral state was hemochorial placentation, while Carter and Mess suggest endotheliochorial placentation. This disagreement is due to differences in taxon sampling (Martin, 2008). In either case, invasiveness is suggested to be ancestral and non-invasive placentation, as found in many hoofed animals and their descendants (e.g. whales), is likely secondary (Wildman et al., 2006).

From this broad scale comparison, the overall phylogenetic framework for discussing the evolution of the endometrial tissue and pregnancy can be summarized as follows: uterine provisioning evolved before vivipary, the uterus is primarily a secretory organ producing nutrients that are absorbed by the fetus through the eggshell. In mammals, vivipary arose before recognition of pregnancy. The marsupial gestation can be characterized as consisting of early intrauterine hatching rather than extended egg retention. Parturition in marsupials is initiated by the fetus (Young et al., 2011), and thus parturition likely evolved before invasive placentation and extended pregnancy. Finally recognition of pregnancy evolved independently in eutherians and in more derived marsupials (e.g. wallaby, Macropodus eugenii). In the following paragraphs, we will focus on the evolutionary changes implied by the comparison between the marsupial and the eutherian endometrium.

\section{The structure and evolution of the marsupial endome- trium}

The principle tissue components of the marsupial endometrium are the same as in the eutherian endometrium: luminal epithelium (LE), uterine glands with glandular epithelia (GE), blood vessels and endometrial stroma (ES) (Fig. 3). The dominant feature of the marsupial endometrium are the endometrial glands, that even further increase in amount and density during pregnancy (Cruz and Selwood, 1993, Cruz and Selwood, 1997, Fleming and Harder, 1981). The stromal compartment is cell poor, with large spaces filled with extracellular matrix (Cruz and Selwood, 1997, Wick and Kress, 2002)(see also Fig. 5.7 in Tyndale-Biscoe and Renfree, 1987).

All marsupials have a yolk sac placenta and a few species also have a chorioallantoic placenta, e.g. the bandicoots Isoodon and Peramelis(Freyer etal., 2003, Mossman, 1987, Padykula and Taylor, 1982 , Tyndale-Biscoe and Renfree, 1987). The yolk sac placenta is divided in two zones, a bilaminar, avascular zone and a trilaminar, vascular zone. The bilaminar yolk sac placenta is thought to be specialized for the absorption of secretions from the endometrial glands, while the trilaminar yolk sac placenta is dedicated to the transfer of gases and nutrients from the maternal blood.

The marsupial fetal-maternal interface is variable. The main variable features concern the early maternal recognition of pregnancy, which is absent in didelphids (opossums) but clearly present in wallaby (Macropus eugenii; (Renfree, 2010)). Among the variable structural features are the kind and extent of cell fusion, in particular whether there is cell fusion of either the trophoblast cells or the luminal epithelial cells, and even the fusion of both trophoblast and endometrial epithelial cells. Also the presence and the nature of trophoblast invasion are variable. To provide an overview we will briefly summarize the situation in three exemplary species: Monodelphis domestica (the gray short-tailed opossum), Isoodon macrourus (bandicoot) and Macropus eugenii (tammar wallaby).

The gray short-tailed opossum belongs to the order Didelphi-

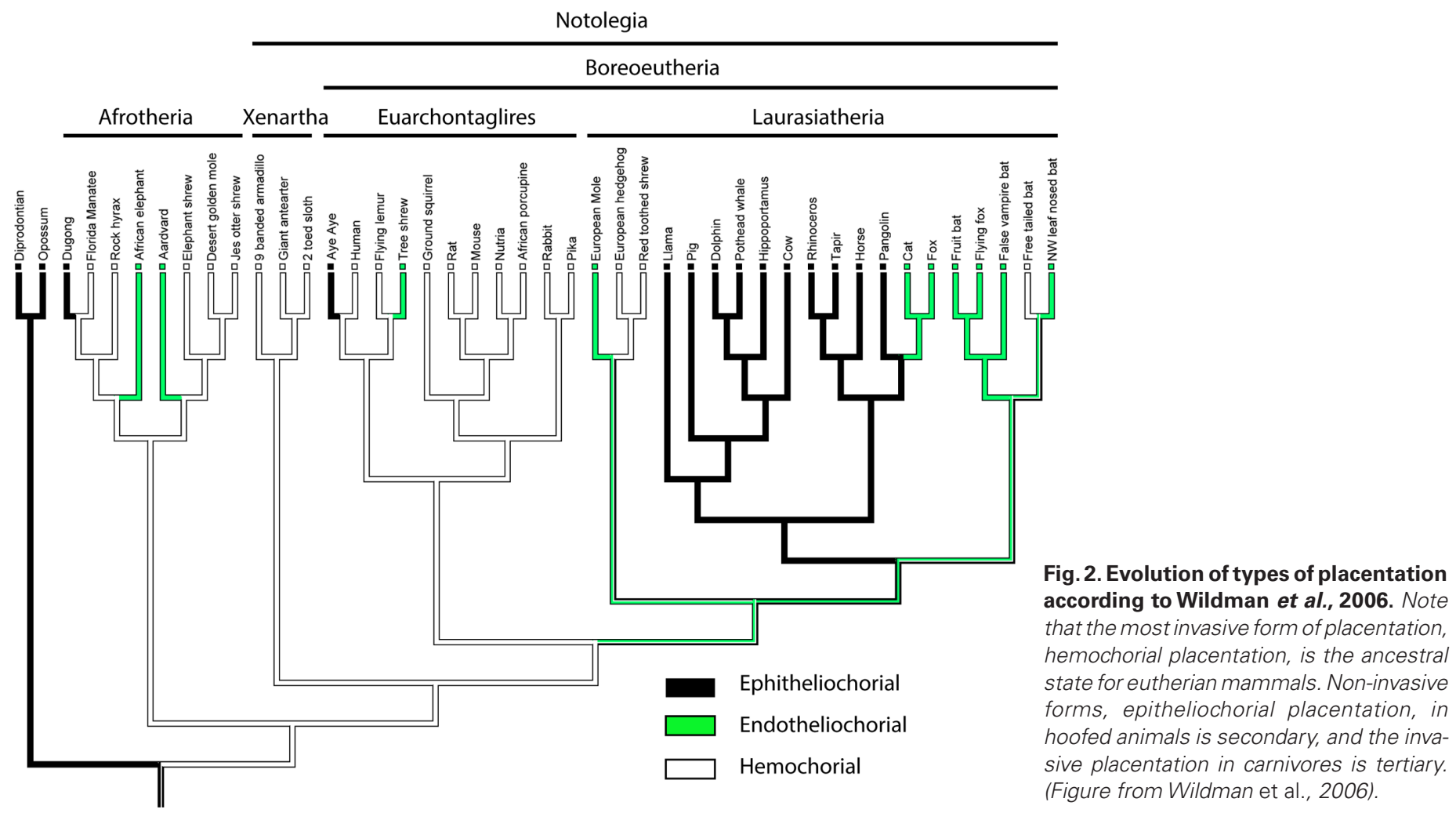




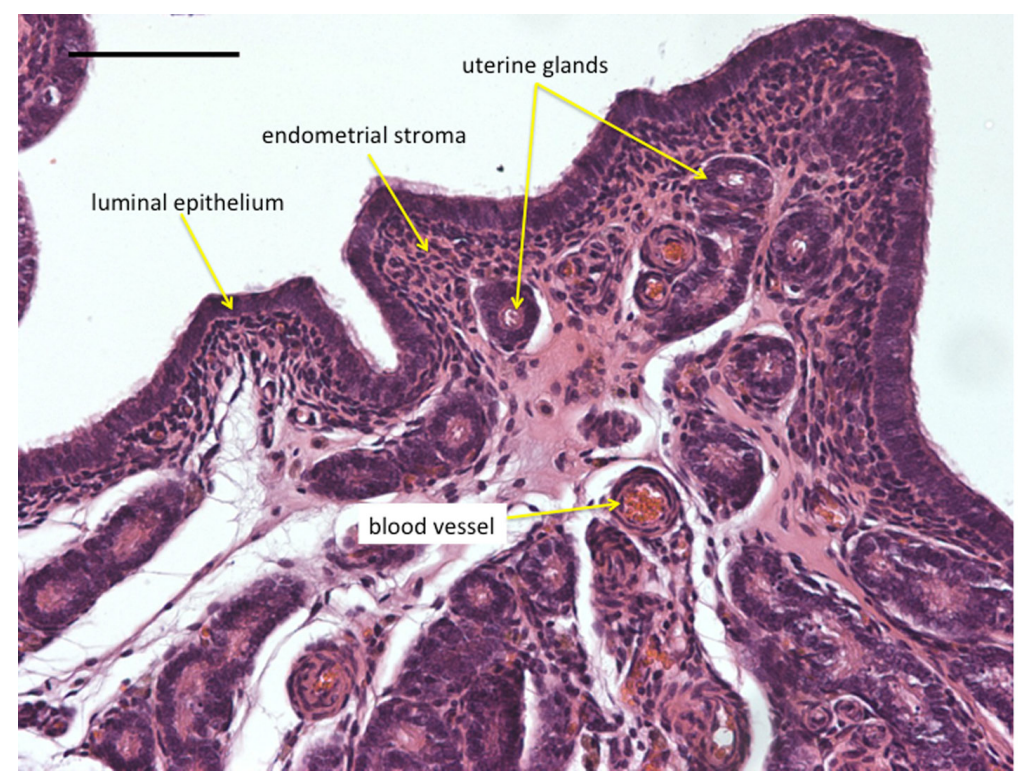

Fig. 3. Histological section through the endometrium of a non-pregnant gray short-tailed opossum (Monodelphis domestica). The main tissue components are a columnar luminal epithelium, a layer of subepithelial endometrial fibroblasts, uterine glands and blood vessels. Scale bar, 100 micrometer.

dae, the most basal branch of the marsupial clade (Beck, 2008, Meredith et al., 2008, Nilsson et al., 2010) and is considered, in many respects, representative of the ancestral marsupial condition (Freyer et al., 2003). Pregnancy in Monodelphis lasts 14 to 15 days post coitum(pc) (Harder et al., 1993), considerably shorter than the sterile sexual cycle of 26.3 days (Fadem and Rayve, 1985), and is not associated with early recognition of pregnancy. Hatching from the shell coat happens by day 12 (Zeller and Freyer, 2001), and the short period of placentation only extends for two to three days during which the trophoblast cells fuse to form a syncytio-trophoblast. Trophblast cell fusion is limited to the trilaminar yolk sac placenta, and the allantois never contacts the chorion. Monodelphisis described to be invasive. Extensions of the syncytio-trophoblast interdigitate between the luminal epithelial cells and directly contact the sub-epithelial maternal capillaries (Fig. 4A). The nature of marsupial invasiveness will be discussed below. Secretory activity and the size of the endometrial glands peaks at about eight days and declines towards parturition and is correlated with the level of circulating progesterone. Stromal cells are associated mainly with the LE and to a lesser degree with the GE (Tyndale-Biscoe and Renfree, 1987). Stromal cell density decreases during pregnancy and, under the luminal epithelium, the stromal cells are replaced by a sub-epithelial net of maternal capillaries (K. Kin and G.P. Wagner, in preparation).

Cyclical changes in the structure of the luminal and glandular epithelia are also occurring during the non-pregnant sexual cycle (Wick and Kress, 2002). In proestrus the LE is a thin $(15 \mu \mathrm{m})$ and tightly packed "palisade" epithelium with dome-shaped apical extensions. During estrus the LE becomes pseudo-stratified and increases in thickness (30 $\mu \mathrm{m})$ with a differentiation into non-ciliated cells with basal elongated nuclei and ciliated cells with large apical nuclei. The LE reaches its maximal thickness of $40 \mu \mathrm{m}$ in post-estrus and decreases again towards met-estrus. These changes in LE are paralleled by similar changes in the GE. The stroma is tightly packed in pro-estrus but turns edematic during estrus, similar to changes during pregnancy. Later macrophages invade the stroma and may play a role in tissue remodeling.

The endometrium and trophoblast of bandicoots (Perameles nasutaand Isoodon macrourus) has been described by Padykula and Taylor (Padykula and Taylor, 1982). Pregnancy of peramelids is even shorter than that of Monodelphis (12.5 days) and they form both a yolk sac as well as an allantois placenta. Blastocyst hatching occurs at about 9 days pc and is associated with cell fusion of the LE cells forming a homokaryon. Fusion of LE cells is also a regular feature of the non-pregnant sexual cycle in bandicoots. During pregnancy the maternal capillaries are placed between the homokaryon cells close to the surface where they meet the trophoblast. The trophoblast cells of the alantoic disc are fusing with the maternal homokaryons to form heterokaryons, i.e. cells where maternal and fetal nuclei occupy the same cytoplasm. The fusion of trophoblast cells with LE homokaryons leads to a situation where the fetal-maternal interface lacks a distinct trophoblast layer and maternal and fetal capillaries come in direct contact with each other.

Pregnancy of the tammar wallaby is considered as highly derived in that the extent of pregnancy is longer than the normal sexual cycle and reaches 26.5 days (Freyer et al., 2002). Extended secretory phase of the uterus are supported by an extended period of elevated levels of circulating progesterone (Renfree, 1972, Renfree, 2010). In the tammar wallaby fertilization happens shortly after birth and the conceptus enters dormancy until the pouch is vacated from the previous generation of offspring. This means that
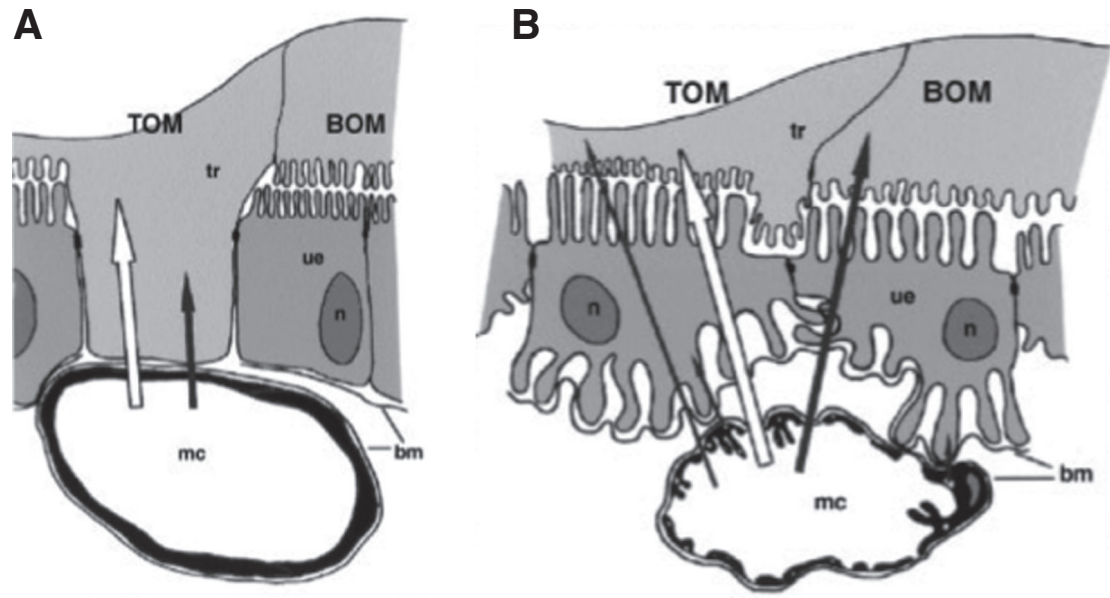

Fig. 4. The fetal-maternal interface in two marsupials. (A) Monodelphis domestica (opossum): trophoblast cells (tr) of the trilaminar part of the yolk sac placenta (TOM) are sending protrusions between the uterine epithelial cells (ue) and directly contact maternal capillaries (mc). (B) Macropus eugenii (tammar wallaby): the uterine epithelial cells get extended sideways and the trophoblast cells extend between the uterine epithelial cells but do not breach the cell junctions between the uterine epithelial cells. Abbreviations: bm, basal membrane; BOM, bilaminar portion of the yolk sac placenta; $n$, nucleus; mc, maternal capillary; ue, uterine epithelium; TOM, trilaminar portion of the yolk sac placenta; tr, trophoblast. (Modified from (Freyer et al., 2003)). 
in order to accommodate extended postnatal care another stage of the maternal cycle is manipulated, namely by the development of the conceptus. Nineteen days after initiation of development the blastocyst hatches and the LE undergoes a transformation from a high columnar epithelium to a sideways stretched extended epithelium (Fig. 4B). Between the LE cells maternal capillaries are intruding, but the junctional complex between neighboring LE cells is never breached (Freyer et al., 2002). Hence the wallaby, though derived in many other ways, has non-invasive placentation, where the maternal and the fetal blood capillaries remain separated by both maternal and fetal epithelia.

Freyer and colleagues presented a phylogenetic analysis of marsupial reproductive characters (Freyer et al., 2003). Their analysis was based on the somewhat outdated phylogenetic hypothesis of Luckett (Luckett, 1994). However, the ancestral character state reconstruction is based on a much simplified tree (Fig. 5), which is still consistent with the phylogenetic hypotheses based on molecular data (Beck, 2008, Nilsson et al., 2010). Many features of didelphid marsupials (among them Monodelphis domestica and Didelphis virginiana) can be considered as likely ancestral for marsupials and perhaps even Theria. These features include: no early recognition of pregnancy, short gestation relative to the sexual cycle, a decrease in secretory activity of the endometrium in the second half of gestation, and poly-ovulation amongst others. In contrast, early maternal recognition of pregnancy, extended gestation, and prolonged secretory activity of the endometrium sustained by extended high levels of circulating progesterone are derived features of macropods (e.g. wallaby) (Fig. 5).

\section{The nature of marsupial "invasive" placentation}

The comparison of opossums, bandicoots and wallabies may suffice to document the extent of variation in terms of marsupial endometrial structure and function and their transformations during pregnancy. This comparison also provides a backdrop for a discussion of marsupial and eutherian invasiveness.

Invasive placentation is usually defined as "erosion or penetration of the luminal epithelium by trophoblast cells" (Mossman, 1987). Following this definition, invasive placentation has been reported in a number of marsupial species, as for instance in Monodelphis (Zeller and Freyer, 2001) and the four-eyed opossum, Philander opossum (Enders and Enders, 1969). There are, however, important differences between the cases of invasiveness described in marsupials and that typical for eutherian species. Marsupial invasiveness is achieved by the penetration of cell extensions from trophoblast cells between LE cells (Monodelphis) (Fig. 4A) or through the fusion of fetal (trophoblast) and maternal (LE) epithelia (bandicoots). Penetration of the LE by cytoplasmatic extension of trophoblast cells has also been described in a non-mammalian species, the South American skink Mabuya (Vieira et al., 2007). The apparent purpose of this form of invasiveness seems to be to bring the maternal and placental blood capillaries into closer proximity, a situation that can also be achieved to some degree without breaching the LE, as is the case in wallaby (Fig. 4B). It is also notable that the invasive phenotypes develop very close to the end of the intrauterine life of the fetus.

In no case of invasive placentation in marsupials are we aware of an extensive interaction between trophoblast cells and endometrial stromal cells. Enders and Enders described, but did not document, in the four eyed opossum, Philander opossum, "slightly enlarged fibroblasts which may constitute a primitive decidual reaction" at the localized sites of LE penetration (Enders and Enders, 1969). In Monodelphis during pregnancy as well during the sexual cycle the stroma becomes edematic and cell poor (Wick and Kress, 2002) and the dense layer of sub-epithelial fibroblast cells essentially disappears (K. Kin and G.P. Wagner, in preparation). Endometrial fibroblasts do exist in marsupials but do not seem to play an important role in the fetal-maternal interface. In contrast, ancestrally in eutherians, the conceptus first establishes contact with the LE and breaches the LE and then establishes a new contact with endometrial stromal cells. The novel interface between the conceptus and the mother is formed by a specialized stromal cell type, the decidual cell, discussed below. An apparent exception in a nonmammalian species is the African lizard Trachylepis ivensi where trophoblast cells penetrate the LE and undermine the LE leading to the complete erosion of LE (Blackburn and Flemming, 2012). Based on this histology a direct contact between trophoblast and the connective tissue that separates the LE from the myometrium seems possible, but the trophoblast remains separated from the maternal tissue by the basal membrane of the LE (Blackburn, personal communication). No decidua-like reaction is observed.

The establishment of a trophoblast-stromal interface seems to be a unique derived character of eutherian mammals with the exception of the skink Trachylepis (see previous paragraph). As mentioned above, according to parsimony based ancestral state reconstructions, the non-invasive placentation of many ferungulates (cows and horses and their relatives) is secondary, a fact that is also supported by the observation of a decidua like reaction in sheep. In the carnuncular regions of the sheep endometrium the LE gets eroded and a direct contact between the binuclear trophoblast cells and the endometrial stroma is established. In these areas the stromal cells show decidual like morphology (Mossman, 1937), and express the decidual markers osteopontin, alpha-smooth muscle actin and desmin (Johnson et al., 2003). The invasive placentation of carnivores (cats and dogs) is tertiary, derived from the secondarily non-invasive placenta, because carnivores are related to hoofed animals (Fig. 2).

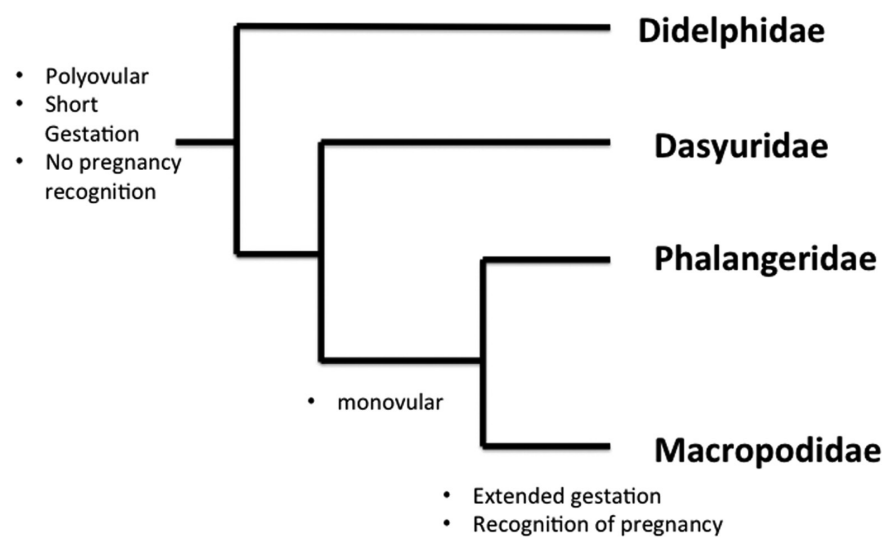

Fig. 5. Phylogenetic relationships among some of the major groups of marsupials. According to this phylogenetic hypothesis the ancestral marsupial and perhaps the ancestral therian animal was polyovular with short gestation and no early recognition of pregnancy. Recognition of pregnancy and extended pregnancy is derived in Macropodidae. (Modified from Freyer et al., 2003). 


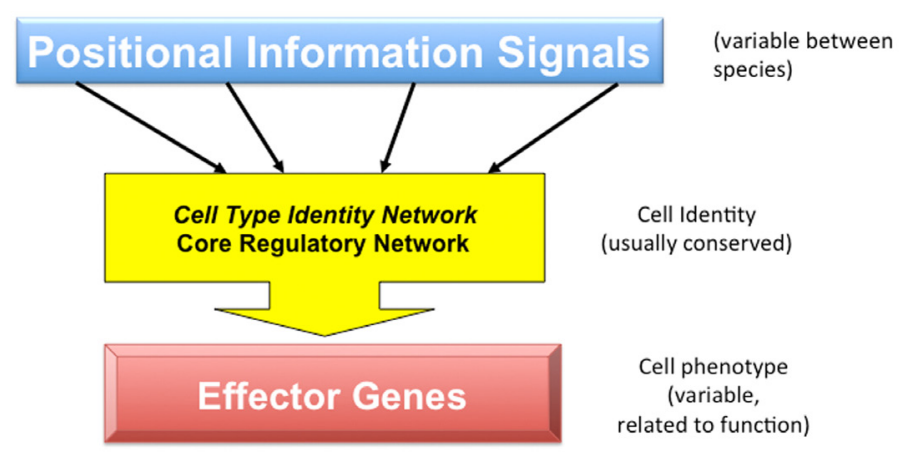

Fig. 6. Three layer model for the development of cell type identity. The top layer consists of signaling events that act upon a core regulatory network (also called a cell type identity network). The genes of the cell type identity network, mostly transcription factor genes, are then acting upon effector genes, i.e. genes that express proteins that do physiological work. Effector genes determine the cell phenotype, while the core regulatory network determines cell type identity. Comparative evidence suggests that the layer of the cell type identity network is more conserved than either the positional information signals or the effector genes. The core gene regulatory network is also abstract with respect to the cell phenotype because the same core regulatory genes can regulate different effector genes and thus lead to different cell phenotypes.

\section{Molecular mechanisms for the evolution of decidual cells}

In eutherian species with invasive placentation endometrial stromal cells differentiate into decidual cells either spontaneously or in response to a fetal signal. Spontaneous decidualization is a phylogenetically derived situation present in higher primates, some bats and the elephant shrew (Emera et al., 2011b). The ancestral situation is that decidualization only occurs in the presence of the conceptus, and can be experimentally triggered, for instance by scratching the emdometrium or by depositing an oil droplet in the uterus. In humans, endometrial stromal cell decidualization is the result of the convergence of two signaling pathways, progesterone stimulation through its nuclear receptor, and the activation of the protein kinase A (PKA) pathway (Gellersen et al., 2007, Gellersen and Brosens, 2003). While the progesterone signal is maternal and likely generally necessary for decidualization, the role of the PKA pathway is less clear. It is tempting to speculate that the PKA pathway is the one ancestrally activated by the conceptus (Emera et al., 2011b).

In human endometrial fibroblasts the response to PKA activation has been described as "categorical reprogramming" (Brar et al., 2001, Tierney et al., 2003). This term suggests a substantial change in the gene regulatory state of the cells upon decidualization rather than a modulation of gene expression of the endometrial fibroblasts. For instance Aghanajova and colleagues have found that cyclic AMP stimulation of human endometrial stromal cells leads to statistically significant expression changes of at least $1.5 x$ of 691 genes including the classical decidualization marker genes $P R L$ and IGFBP1 as well as the key decidual regulator FOXO1A(Aghajanova et al., 2010). This transcriptional response is consistent with the idea that decidual cells are a cell type distinct from that of endometrial fibroblast cells. Data about the chromatin modification and transcription factor co-localization are also consistent with that view (M. Nnamani and G.P. Wagner, in preparation).
Different cell types can be understood as cells that differ with respect to the activity of a core gene regulatory network that enables differential expression of effector genes (Graf and Enver, 2009, Wagner, 2014) (Fig. 6). These core regulatory networks mediate between external signals and the expression of effector genes, where effector genes are those that produce molecules that perform physiological functions (enzymes, matrix proteins etc). Core gene regulatory networks usually comprise genes that are mutually auto- and co-regulatory transcription factor or transcriptional co-factor genes. Some of the transcription factors regulate their target genes cooperatively, i.e. are jointly necessary to effect target gene expression. Another important function of core transcription factor genes is the suppression of alternative gene regulatory network states (Graf and Enver, 2009). Further evidence that decidual cells are a distinct cell type that originated in the stem lineage of eutherian mammals is provided by the comparative study of gene regulation. These data reflect the evolution of transcription factor cooperativity and the history of target gene expression in decidual cells.

In human endometrial stromal cells PRL is a classical decidualization marker. The expression of decidual PRL(dPRL) is regulated by an alternative promoter about $6 \mathrm{~kb}$ upstream of the first coding exon (Berwaer et al., 1994, Gellersen et al., 1994) that is derived from two transposable elements (Emera et al., 2011a, Emera and Wagner, 2012, Gerlo et al., 2006). A number of transcription factors have been identified that participate in the regulation of dPRL. These include, ETS1, HOXA11, CEBPB, FOXO1A and PGR (Christian et al., 2002a, Christian et al., 2002b, Lynch et al., 2009, Pohnke et al., 1999). The regulatory effects of HoxA11 and CEBPB on $\mathrm{APRL}$ depend on a cooperative interaction of them with FOXO1A (Lynch et al., 2009, Lynch et al., 2008). Both of these interactions, the interactions between HOXA11 and FOXO1A as well as CEBPB and FOXO1A, evolved in the stem lineage of eutherian mammals (Lynch et al., 2011b, Lynch et al., 2008). This has been demonstrated by the comparison of the regulatory activity of different mammalian (human, mouse, opossum, platypus) and non-mammalian (chicken) HOXA11 and CEBPB transcription factors on a reporter gene construct with the human $\mathrm{dPRL}$ promoter/enhancer. In addition, ancestrally, reconstructed and physically re-constituted transcription factor proteins have been tested, confirming the conclusion that the transcription factor cooperativity evolved in the stem lineage of eutherian mammals (Fig. 7). Specifically, the ancestral therian (most recent common ancestor of marsupials and eutherians) proteins and all non-eutherian proteins are unable to up-regulate reporter gene expression from the dPRL promoter/enhancer. In contrast, the ancestral eutherian protein as well as the human and mouse proteins can upregulate reporter gene expression (Fig. 7). It has also been shown that the physical protein-protein interaction between FOX01A and HOXA11 and CEBPB is phylogenetically older than the functional interaction (HOXA11: (Brayer et al., 2011); CEBPB: (Lynch et al., $2011 b)$ ). Overall these results show that functional transcription factor interactions essential for decidual gene expression evolved coincidental with invasive placentation. This is consistent with the hypotheses that 1) the decidual cell is a distinct cell type with cell type specific transcription factor cooperativity and 2) that this cell type evolved in the stem lineage of eutherian mammals.

Another criterion to support the notion that the decidual cell is a distinct cell type is the independent evolution of cell type 


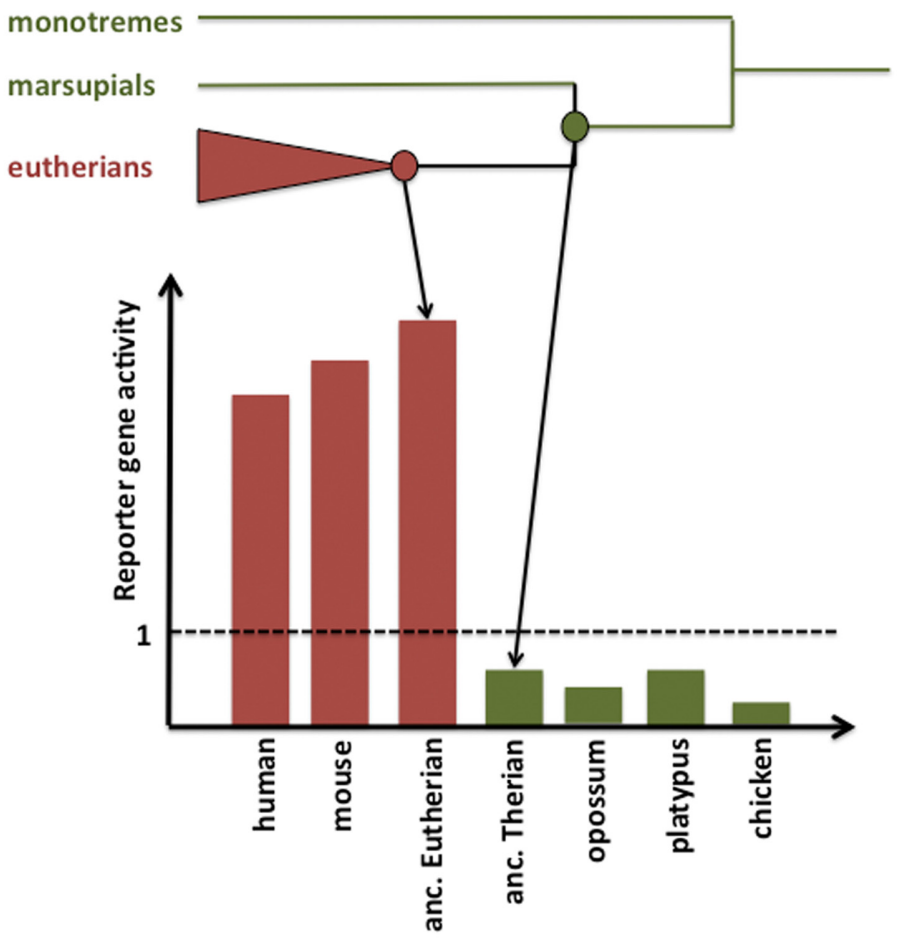

Fig. 7. Evolution of decidual transcription factor activity of HOXA11. HOXA11 interacts with FOXO1A to activate decidual target genes, for instance decidual prolactin (dPRL). These results used the $d P R L$ promoter of humans. Human, mouse and ancestral eutherian HOXA11 are able to activate reporter gene expression from the human $d P R L$ promoter, but ancestral therian, opossum, platypus and chicken HOXA11 proteins do not. This shows that transcription factor cooperativity, necessary for decidual gene expression, evolved in the stem lineage of eutherian mammals. (Modified from (Lynch et al., 2008)).

specific transcriptome (Wagner, 2014). The core gene regulatory networks that distinguish different cell types enable differential target gene expression and thus also quasi-independent evolution of the transcriptome of a given cell type compared to other cell types (Wagner, 2014). In the case of decidual cells, target gene recruitment is, at least in part, mediated through the evolution of alternative promoters and cell type specific enhancers from transposable elements. This was first discovered for the decidual promoter of PRL (Emera et al., 2011a, Emera and Wagner, 2012, Gerlo et al., 2006, Lynch et al., 2011a). The decidual promoter consists of DNA from two transposable elements, MER20 and MER39 (Gerlo et al., 2006). MER20 is an element that is only found in eutherians, and MER39 a transposable element that only exists in Archontoglires (the clade that unites primates and rodents) (Emera et al., 2011a). These elements underwent considerable modification until the strong and fast responding dPRL promoter characteristic of apes and humans evolved (Emera and Wagner, 2012). Furthermore, the recruitment of $P R L$ into decidual cells evolved at least three times independently, in primates, rodents and afrotherians (elephants) (Emera et al., 2011a). Each time a different alternative promoter evolved and each time the promoter arose from a different transposable element. An analysis of the genomic distribution of MER20 transposable elements supports the hypothesis that other decidual genes also have been recruited through the modification of MER20 transposable elements (Lynch etal., 2011a). These results show that the transcriptome of decidual cells is actively evolving in part enabled through the recruitment of transposable elements into cis-regulatory functions.

The results summarized above support the notion that a) decidual cells are a distinct cell type from endometrial stromal fibroblasts, and b) that decidual cell type identity has evolved in the stem lineage of eutherian mammals (Fig. 1).

\section{Key innovations in the evolution of eutherian pregnancy}

Here we want to summarize the implications of the above evidence for the evolutionary origin of eutherian pregnancy and embryo implantation. Many questions are still unanswered but never the less a few key features can be discerned.

Based on the situation in basal marsupial lineages, as represented in the laboratory opossum, Monodelphis domestica, it seems likely that in the mammalian lineage vivipary initially evolved without maternal recognition of early pregnancy. If the basal marsupial situation was characteristic also for the ancestral therians, then vivipary initially arose as a precocious intrauterine hatching event, where the fetus hatches from the eggshell into the uterus a few days before extrusion, initially giving birth to a very immature neonate. In opossums one cannot even speak of a true pregnancy, because the physiology of the mother does not notably change in the presence of a conceptus. Many of the endometrial changes associated with pregnancy also occur in the sterile sexual cycle (see above) and progesterone does not have a consistent influence on the length of pregnancy (Bradshaw and Bradshaw, 2011, Tyndale-Biscoe and Renfree, 1987), a situation reminiscent of that in viviparous lizards (Albergotti and Guillette, 2011). Aconsequence of this scenario is that parturition is phylogenetically older than pregnancy, and certainly older than the mechanisms that extend pregnancy in eutherians and derived marsupials. In Eutherians the maintenance of pregnancy critically depends on sustained high levels of circulating progesterone (Csapo et al., 1972, Csapo et

\section{Vivipary through egg-retention:}

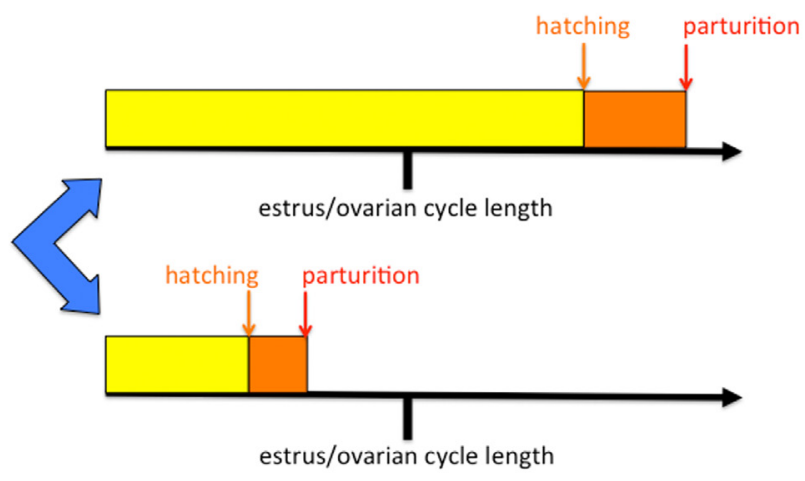

Vivipary through precocious hatching \& parturition:

Fig. 8. Two modes for the evolution of vivipary: egg retention and precocious hatching and parturition (PH\&P). Egg retention is the predominant mode of gestation in squamates, even in oviparous species. PH\&P is the mode found in basal marsupial species such as the opossum. The important difference is that egg retention requires some kind of recognition of gestation to prevent premature oviposition, while PH\&P can occur without recognition of pregnancy. Recognition of pregnancy in mammals is secondary and only necessary when extended gestation evolves. 
al., 1973). The consequences of this hypothesis will be discussed in greater detail elsewhere (M. Pavličev, in preparation).

The comparison of gestation of basal marsupials, specifically the didelphids, which are the most basal lineage of the marsupial tree, and that in viviparous reptiles (Albergotti and Guillette, 2011, Van Dyke et al., 2014) suggests that we need to distinguish two pathways to vivipary (Blackburn, 2006): egg retention and precocious hatching and parturition (PH\&P). In viviparous reptiles the evolution of vivipary is initiated by egg-retention (Albergotti and Guillette, 2011, Blackburn, 2006), i.e. extension of the residence time of the egg in the female reproductive tract until fetal development is completed (Fig. 8). Extended egg retention is correlated with gradual thinning of the eggshell, but egg retention is not limited to viviparous species. Squamates are the group with the largest number of independently derived cases of vivipary, about 100 times (Blackburn, 2006, Van Dyke et al., 2014). In squamates even oviparous species retain the egg longer than the ovarian cycle of the species and there is a broad overlap in the distribution of gestation times among oviparous and viviparous species (Tinkle and Gibbons, 1977). Hence, in squamates, egg-retention is likely an ancestral character that is extended to lead to vivipary. A recent phylogenetic analysis even suggests that viviparity might be ancestral for squamates (Pryon and Burbrink, 2014).

In contrast, the situation in basal marsupials is one where the egg is hatching very early in utero, and parturition happens while the fetus is still quite immature (Freyer et al., 2003, Tyndale-Biscoe and Renfree, 1987). As the example of the macropodids shows, from this starting point, early hatching and parturition, more extensive gestation can evolve by extending of the period of fetus retention (Renfree, 2010). The main difference between egg retention and PH\&P is that the former requires some kind of change in the maternal physiology to prevent premature oviposition. In contrast PH\&P is an event that initially occurs within a fraction of the normal sexual cycle, and no early recognition of pregnancy is necessary. Timing of parturition in under the control of the fetus in marsupials (Young et al., 2011), while how parturition is regulated in reptiles is unknown (Albergotti and Guillette, 2011). Hence, the evolutionary pathway to vivipary in mammals and squamates has proceeded along different pathways and likely involved different mechanisms (Blackburn, 2006).

Key innovations that led to the extended retention of the fetus characteristic of eutherian mammals evolved in the stem lineage of eutherian mammals, i.e. after the most recent common ancestor of therians and before the most recent common ancestor of eutherians. These are:

- Early recognition of pregnancy leading to an extension of luteal progesterone production.

- Invasive placentation which led to a derived direct interaction between trophoblast and endometrial stromal cells.

- Evolution of the decidual cell type to control both the invasion of the trophoblast cells as well as suppressing the maternal immune and inflammatory reactions.

Various forms of minimal invasiveness have been described in marsupials and squamates (see above), but they are all late during gestation and do not lead to a direct interface between trophoblast and endometrial stromal cells. Marsupial and squamate invasiveness leads to a closer proximity of maternal and fetal blood vessels and sometimes even to the fusion of endometrial luminal epithelial cells and fetal trophoblast cells (e.g. bandicoots). From a developmental point of view, however, the crucial difference between marsupial and eutherian placentation is the derived direct interaction between trophoblast cells and endometrial stromal cells. A likely consequence of this derived cell-cell interaction is the origin of the decidual cell type. Most of the molecular events that led to the origin of the decidual cell type are still unknown, except the well documented evolution of novel transcription factor interactions (Lynch et al., 2008, 2011b and Brayer et al., 2011) that, in eutherians, are necessary for the regulation of decidual gene expression. The most urgent open questions in this area are: 1) what is the structure of the decidual core regulatory network? and 2) what were the molecular events that led to the origin of the decidual core network?

\section{Acknowledgements}

Research in the Wagner lab that led to the results described in this review was supported by a grant of the John Templeton Foundation (Grant number: 12793) as well as support by the Yale University science development fund. The opinions expressed in this paper are not these of the John Templeton Foundation.

\section{References}

AGHAJANOVA, L., HORCAJADAS, J.A., WEEKS, J.L., ESTEBAN, F.J., NEZHAT, C.N., CONTI, M. and GIUDICE, L.C. (2010). The protein kinase A pathwayregulated transcriptome of endometrial stromal fibroblasts reveals compromised differentiation and persistent proliferative potential in endometriosis. Endocrinol. 151: $1341-55$

ALBERGOTTI, L.C. and GUILLETTE, L.J. (2011). Vivipary in reptiles: evolution and reproductive endocrinology. In Hormones and Reproduction of Vertebrates, vol. 3 (ed. NORRIS, D. O. and LOPEZ, K. H.). Academic Press, Amsterdam, pp.247-275.

BECK, R.M.D. (2008). Adated phylogeny of marsupials using a molecular supermatrix and multiple fossil constraints. J. Mammalogy 89: 175-189.

BERWAER, M., MARTIAL, J.A. and DAVIS, J.R. (1994). Characterization of an upstream promoter directing extrapituitary expression of the human prolactin gene. Mol Endocrinol 8: 635-42.

BLACKBURN, D.G. (1992). Convergent evolution of vivipary, matrotrophy, and specializations for fetal nutrition in reptiles and other vertebrates.. Amer. Zool. 32: 313-321.

BLACKBURN, D.G. (2006). Squamate reptiles as model organisms for the evolution of vivipary. Herpetol Monogr 20: 131-146.

BLACKBURN, D.G. and FLEMMING, A.F. (2009). Morphology, development, and evolution of fetal membranes and placentation in squamate reptiles. $J$ Exp Zool B Mol Dev Evol 312: 579-89.

BLACKBURN, D.G. and FLEMMING, A.F. (2012). Invasive implantation and intimate placental associations in a placentotrophic African lizard, Trachylepis ivensi (scincidae). J Morphol 273: 137-59.

BRADSHAW, F.J. and BRADSHAW, D. (2011). Progesterone and reproduction in marsupials: a review. Gen Comp Endocrinol 170: 18-40.

BRAR, A.K., HANDWERGER, S., KESSLER, C.A. and ARONOW, B.J. (2001). Gene induction and categorical reprogramming during in vitro human endometria fibroblast decidualization. Physiol Genomics 7: 135-48

BRAYER, K.J., LYNCH, V.J. and WAGNER, G.P. (2011). Evolution of a derived protein-protein interaction between HoxA11 and Foxo1a in mammals caused by changes in intramolecular regulation. Proc Natl Acad Sci USA 108: E414-20.

CHRISTIAN, M., POHNKE, Y., KEMPF, R., GELLERSEN, B. and BROSENS, J.J. (2002a). Functional association of PR and CCAAT/enhancer-binding protein beta isoforms: promoter-dependent cooperation between PR-B and liver-enriched inhibitory protein, or liver-enriched activatory protein and PR-A in human endometrial stromal cells. Mol Endocrinol 16: 141-54.

CHRISTIAN, M., ZHANG, X., SCHNEIDER-MERCK, T., UNTERMAN, T.G. GELLERSEN, B., WHITE, J.O. and BROSENS, J.J. (2002b). Cyclic AMP-induced forkhead transcription factor, FKHR, cooperates with CCAAT/enhancer-binding protein beta in differentiating human endometrial stromal cells. J. Biol. Chem. 277: 20825-20832 
CRAWFORD, N.G., FAIRCLOTH, B.C., MCCORMACK, J.E., BRUMFIELD, R.T., WINKER, K. and GLENN, T.C. (2012). More than 1000 ultraconserved elements provide evidence that turtles are the sister group of archosaurs. Biol. Lett. 8:783-786.

CRUZ, Y.P. and SELWOOD, L. (1993). Uterine histology of the dasyurid marsupial, Antechinus stuartii: relationship with differentiation of the embryo. $J$ Reprod Fertil 99: 237-42.

CRUZ, Y.P. and SELWOOD, L. (1997). Histological differences between gravid and non-gravid uteri in the dasyurid marsupial, Sminthopsis macroura (Spencer). $J$ Reprod Fertil 111: 319-25.

CSAPO, A.I., PULKKINEN, M.O., RUTTNER, B., SAUVAGE, J.P. and WIEST, W.G. (1972). The significance of the human corpus luteum in pregnancy maintenance. I. Preliminary studies. Am J Obstet Gynecol 112: 1061-7.

CSAPO, A.I., PULKKINEN, M.O. and WIEST, W.G. (1973). Effects of luteectomy and progesterone replacement therapy in early pregnant patients. Am J Obstet Gynecol 115: 759-65.

ELLIOT, M.G. and CRESPI, B.J. (2009). Phylogenetic evidence for early hemochorial placentation in eutheria. Placenta 30: 949-67.

EMERA, D., CASOLA, C., LYNCH, V.J., WILDMAN, D.E., AGNEW, D. and WAGNER, G.P. (2011a). Convergent evolution of endometrial prolactin expression in primates, mice, and elephants through the independent recruitment of transposable elements. Mol Biol Evol 29: 239-47.

EMERA, D., ROMERO, R. and WAGNER, G. (2011b). The evolution of menstruation: a new model for genetic assimilation: explaining molecular origins of maternal responses to fetal invasiveness. Bioessays 34: 26-35.

EMERA, D. and WAGNER, G.P. (2012). Transformation of a transposon into a derived prolactin promoter with function during human pregnancy. Proc Natl Acad Sci USA 109: 11246-51.

ENDERS, A.C. and ENDERS, R.K. (1969). The placenta of the four-eye opossum (Philander opossum). Anat Rec 165: 431-49.

FADEM, B.H. and RAYVE, R.S. (1985). Characteristics of the oestrous cycle and influence of social factors in grey short-tailed opossums (Monodelphis domestica). J Reprod Fertil 73: 337-42.

FLEMING, M.W. and HARDER, J.D. (1981). Uterine histology and reproductive cycles in pregnant and non-pregnant opossums, Didelphis virginiana. $J$ Reprod Fertil 63: 21-4.

FREYER, C., ZELLER, U. and RENFREE, M.B. (2002). Ultrastructure of the placenta of the tammar wallaby, Macropus eugenii: comparison with the grey short-tailed opossum, Monodelphis domestica. J Anat 201: 101-19.

FREYER, C., ZELLER, U. and RENFREE, M.B. (2003). The marsupial placenta: A phylogenetic analysis. J. Exp. Zool. J. Exp. Zool. 299A: 59-77.

GELLERSEN, B., BROSENS, I.A. and BROSENS, J.J. (2007). Decidualization of the human endometrium: mechanisms, functions, and clinical perspectives. Semin Reprod Med 25: 445-53.

GELLERSEN, B. and BROSENS, J. (2003). Cyclic AMP and progesterone receptor cross-talk in endometrium: a decidualizing affair. J. Endocrinology 178: 357-372.

GELLERSEN, B., KEMPF, R., TELGMANN, R. and DIMATTIA, G.E. (1994). Nonpituitary human prolactin gene transcription is independent of Pit-1 and differentially controlled in lymphocytes and in endometrial stroma. Mol Endocrinol 8: 356-73.

GERLO, S., DAVIS, J.R., MAGER, D.L. and KOOIJMAN, R. (2006). Prolactin in man: a tale of two promoters. Bioessays 28: 1051-5.

GRAF, T. and ENVER, T. (2009). Forcing cells to change lineages.. Nature 462: 587-594. GRIFFITHS, M. (1978). The Biology and Monotremes. Academic Press, San Diego, CA.

HARDER, J.D., STONEROOK, M.J. and PONDY, J. (1993). Gestation and placentation in two New World opossums: Didelphis virginiana and Monodelphis domestica. $J$ Exp Zool 266: 463-79.

JOHNSON, G.A., BURGHARDT, R.C., JOYCE, M.M., SPENCER, T.E., BAZER, F.W., PFARRER, C. and GRAY, C.A. (2003). Osteopontin expression in uterine stroma indicates a decidualization-like differentiation during ovine pregnancy. Biol Reprod 68: 1951-8.

JONES, R.E., GUILLETTE, L.J., JR., SUMMERS, C.H., TOKARZ, R.R. and CREWS, D. (1983). The relationship among ovarian condition, steroid hormones, and estrous behavior in Anolis carolinensis. J Exp Zool 227: 145-54.

LOMBARDI, J. (1998). Comparative Verbebrate Reproduction. Kluwer Academic Publishers, Boston
LUCKETT, W.P. (1994). Suprafamiliar relationships within Marsupialia: resolution and discordance from multidisciplinary data. J. Mammal Evol. 2: 255-283.

LYNCH, V.J., BRAYER, K., GELLERSEN, B. and WAGNER, G.P. (2009). HoxA-11 and $\mathrm{FOXO1A}$ cooperate to regulate decidual prolactin expression: towards inferring the core transcriptional regulators of decidual genes. PLoS One 4: e6845.

LYNCH, V.J., LECLERC, R.D., MAY, G. and WAGNER, G.P. (2011a). Transposonmediated rewiring of gene regulatory networks contributed to the evolution of pregnancy in mammals. Nat Genet 43: 1154-9.

LYNCH, V.J., MAY, G. and WAGNER, G.P. (2011b). Regulatory evolution through divergence of a phosphoswitch in the transcription factor CEBPB. Nature 480:383-6.

LYNCH, V.J., TANZER, A., WANG, Y., LEUNG, F.C., GELLERSEN, B., EMERA, D. and WAGNER, G.P. (2008). Adaptive changes in the transcription factor HoxA-11 are essential for the evolution of pregnancy in mammals.. Proc. Natl. Acad. Sci USA 105: 14928-14933.

MARTIN, R.D. (2008). Evolution of placentation in primates: Implications of mammalian phylogeny. Evol Biol 35: 125-145.

MEREDITH, R.W., WESTERMAN, M., CASE, J.A. and SPRINGER, M.S. (2008). A Phylogeny and timescale for marsupial evolution based on sequences for five nuclear genes. J. Mammal. Evol.15: 1-36.

MESS, A. and CARTER, A.M. (2006). Evolutionary transformation of fetal membrane characters in Eutheria with special reference to Afrotheria. J Exp Zool Part B (Mol Dev Evol) 306B: 140-163.

MOSSMAN, H.W. (1937). Comparative morphogenesis of the foetal membranes and accessory uterine structures. Contr. Embyol. 26: 129-246.

MOSSMAN, H.W. (1987). Vertebrate Fetal Membranes. Rutgers University Press New Brunswick, NJ.

NILSSON, M.A., CHURAKOV, G., SOMMER, M.,TRAN, N.V.,ZEMANN, A., BROSIUS, J. and SCHMITZ, J. (2010). Tracking marsupial evolution using archaic genomic retroposon insertions. PLOS Biol 8: e1000436.

PADYKULA, H.A. and TAYLOR, J.M. (1982). Marsupial placentation and its evolutionary significance. J Reprod Fertil Supp/31: 95-104.

POHNKE, Y., KEMPF, R. and GELLERSEN, B. (1999). CCAAT/enhancer-binding proteins are mediators in the protein kinase $A$-dependent activation of the decidual prolactin promoter. J Biol Chem 274: 24808-18.

PYRON, R.A. and BURBRINK, F.T. (2014). Early origin of viviparity and multiple reversion to oviparity in squamate reptiles. Ecology Lett. 17: 13-21.

RENFREE, M.B. (1972). Influence of the embryo on the marsupial uterus. Nature 240: 475-7.

RENFREE, M.B. (2010). Marsupials: Placental Mammals with a Difference. Placenta 31: S21-S26.

SCHATTEN, H. and CONSTANTIENSCU, G.H. (2007). Comparative Reproductive Biology. Blackwell Pub., Ames, lowa.

TIERNEY, E.P., TULAC, S., HUANG, S.-T.J. and L. C, G. (2003). Activation of the protein kinase A pathway in human endometrial stromal cells reveals sequential categorical gene regulation. Physiol. Genomics 16: 47-66.

TINKLE, D.W. and GIBBONS, H.W. (1977). The Distribution and Evolution of Vivipary in Reptiles. Museum of Zoology, University of Michigan, Ann Arbor, MI.

TYNDALE-BISCOE, C.H. and RENFREE, M.B. (1987). Reproductive Physiology of Marsupials. Cambridge University Press, Cambridge, UK.

VAN DYKE, J.U., BRANDLEY, M.C. and THOMPSON, M.B. (2014). The evolution of viviparity: molecular and genomic data from squamate reptiles advance understanding of live birth in amniotes. Reproduction 147: R15-26.

VIEIRA, S., DE PEREZ, G. and RAMIREZ-PINILLA, M.P. (2007). Invasive cells in the placentome of Andean populations of Mabuya: an endotheliochorial contribution to the placenta? Anat Rec (Hoboken) 290: 1508-18.

WAGNER, G.P. (2014). Homology, Genes and Evolutionary Innovation. Princeton University Press, Princeton, NJ.

WANG, Z., PASCUAL-ANAYA, J., ZADISSA, A., LI, W.Q., NIIMURA, Y., HUANG, Z.Y. LI, C.Y., WHITE, S., XIONG, Z.Q., FANG, D.M. et al., (2013). The draft genomes of soft-shell turtle and green sea turtle yield insights into the development and evolution of the turtle-specific body plan. Nature Genet. 45: 701-706.

WICK, R. and KRESS, A. (2002). Ultrastructural changes in the uterine luminal and glandular epithelium during the oestrous cycle of the marsupial Monodelphis domestica (grey short-tailed opossum). Cells Tissues Organs 170: 111-31. 


\section{G.P. Wagner et al.}

WILDMAN, D.E., CHEN, C., EREZ, O., GROSSMAN, L.I., GOODMAN, M. and R, R. (2006). Evolution of the mammalian placenta revealed by phylogenetic analysis. Proc. Natl. Acad. Sci USA 103: 3203-3208.

WOURMS, J.P. (1977). Reproduction and development in chondrichthyan fishes. Amer. Zool. 17: 379-410.

WOURMS, J.P. (1981). Viviparity: the maternal-fetal relationship in fishes. Amer. Zool. 21: 473-515.
YOUNG, I.R., RENFREE, M.R., MESIANO, S., SHAW, G., JENKIN, G. and SMITH, R. (2011). The comparative physiology of parturition in mammals: hormones and parturition in mammals.. In Hormones and Reproduction of Vertebrates: Mammals, vol. 5 (ed. NORRIS, D. O. and LOPEZ, K. H.). Academic Press, Amsterdam, pp.95-116.

ZELLER, U. and FREYER, C. (2001). Early ontogeny and placentation of the grey short-tailed opossum, Monodelphis domestica (Didelphidae: Marsupialia): contribution to the reconstruction of the marsupial morphotype. J Zool Syst Evol Res 39: 137-158. 
Further Related Reading, published previously in the Int. J. Dev. Biol.

Akt1 and insulin-like growth factor 2 (Igf2) regulate placentation and fetal/postnatal development

Lindsey N. Kent, Shigeki Ohboshi and Michael J. Soares

Int. J. Dev. Biol. (2012) 56: 255-261

http://dx.doi.org/10.1387/ijdb.113407lk

The hidden maternal-fetal interface: events involving the lymphoid organs in maternal-fetal tolerance

Int. J. Dev. Biol. (2010) 54: 421-430

http://dx.doi.org/10.1387/ijdb.082800et

On the role of placental major histocompatibility complex and decidual leukocytes in implantation and pregnancy success using non-human primate models Thaddeus G. Golos, Gennadiy I. Bondarenko, Svetlana V. Dambaeva, Edith E. Breburda, and Maureen Durning

Int. J. Dev. Biol. (2010) 54: 431-443

http://dx.doi.org/10.1387/ijdb.082797tg

Split immunological tolerance to trophoblast

Amanda de Mestre, Leela Noronha, Bettina Wagner and Douglas F. Antczak

Int. J. Dev. Biol. (2010) 54: 445-455

http://dx.doi.org/10.1387/ijdb.082795ad

Role of fetal membranes in signaling of fetal maturation and parturition Leslie Myatt and Kang Sun

Int. J. Dev. Biol. (2010) 54: 545-553

http://dx.doi.org/10.1387/ijdb.082771lm
Elizabeth S. Taglauer, Kristina M. Adams Waldorf and Margaret G. Petroff
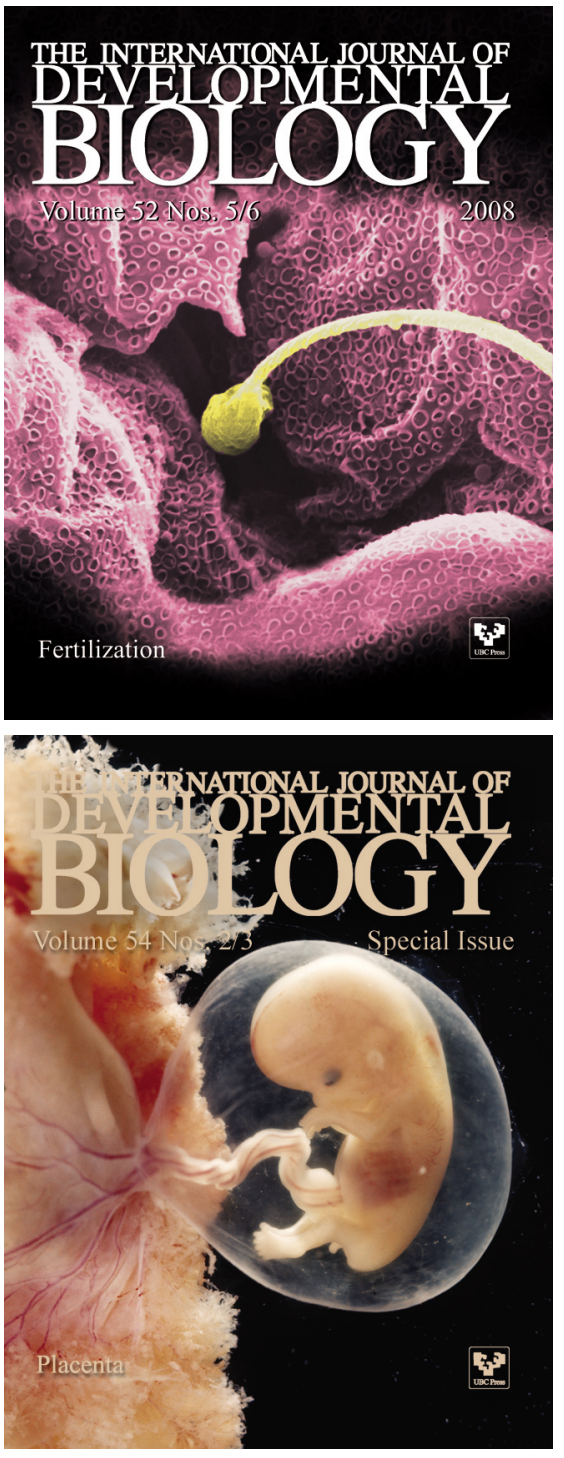

5 yr ISI Impact Factor $(2011)=2.959$
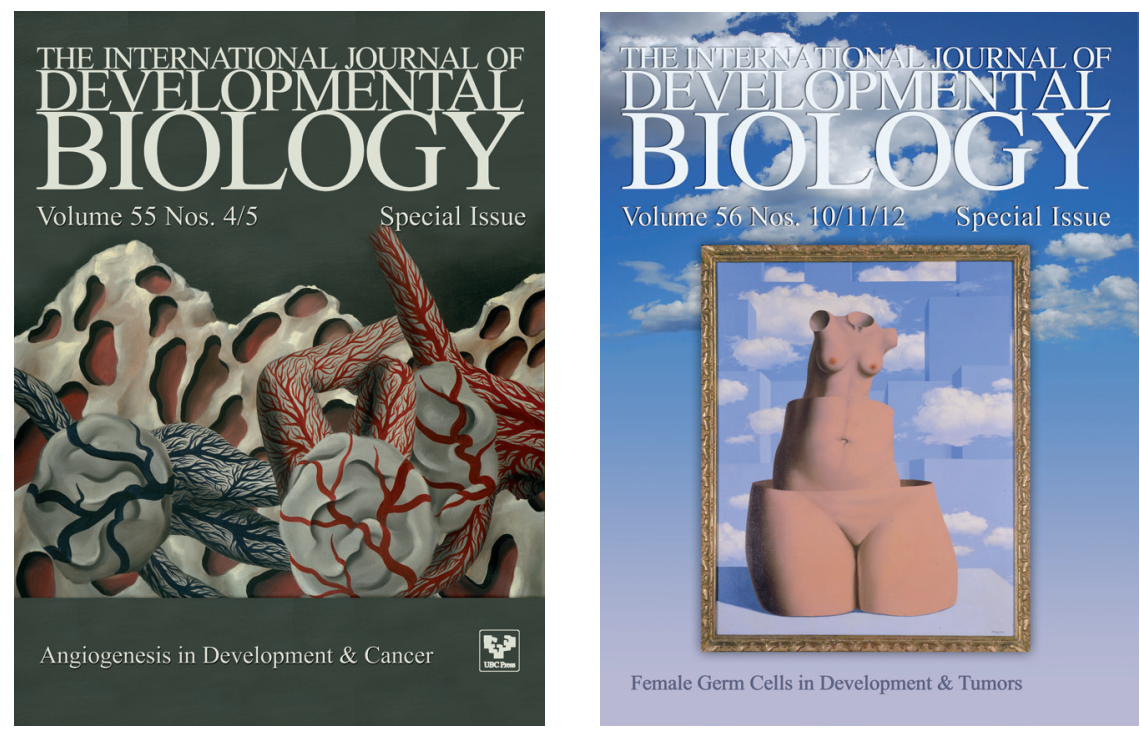

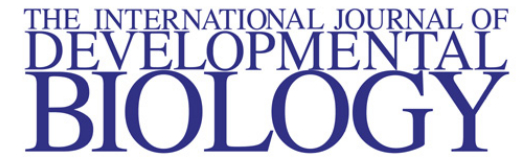

Volume 48 Nos. $5 / 6$

Special issue

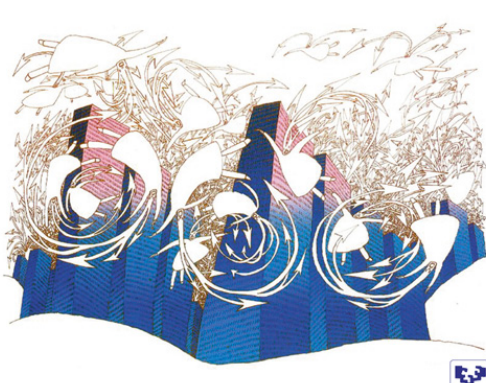

Invasion in cancer and embryonic development 